\title{
Erratum to: Textile Reinforced Concrete: experimental investigation on design parameters
}

\author{
Isabella Giorgia Colombo • Anna Magri • \\ Giulio Zani · Matteo Colombo · Marco di Prisco
}

Published online: 4 April 2013

(C) RILEM 2013

\begin{abstract}
Textile Reinforced Concrete (TRC) is an advanced cement-based material in which fabrics used as reinforcement can bring significant loads in tension, allowing architects and engineers to use thin crosssections. Previous research projects, developed during the last 10 years mainly in Germany, Israel and the USA, have shown the capabilities of such a material. In this paper an extensive experimental investigation of TRC is presented: tensile tests were carried out to obtain a complete mechanical characterization of the composite material under standard conditions, considering the influence of different variables such as
\end{abstract}

Due to an unfortunate turn of events this article was published with wrong citations in the text to the references at the end of the article. In order to provide the correct information this article is hereafter published in its entirety with the correct citations and should be regarded as the final version by the reader.

The online version of the original article can be found under doi:10.1617/s11527-013-0017-5.

I. G. Colombo $(\bowtie) \cdot$ A. Magri · G. Zani ·

M. Colombo - M. di Prisco

Department of Civil and Environmental Engineering,

Politecnico di Milano, Milan, Italy

e-mail: isabella.colombo@mail.polimi.it

URL: www.polimi.it

A. Magri

e-mail: anna.magri@mail.polimi.it

G. Zani

e-mail: giulio.zani@mail.polimi.it reinforcement ratio, fabric geometry, curing conditions, displacement rate and specimen size.

Keywords Textile Reinforced Concrete (TRC) Uniaxial tension - Weft spacing · Curing conditions · Displacement rate $\cdot$ Specimen size

\section{Introduction}

Textile Reinforced Concrete (TRC) is a composite cement-based material reinforced with Alkali Resistant (AR) glass, carbon or aramid fabrics. The combination of fabrics and fine-grained concrete, which in fact resembles more a mortar than a concrete, allows architects and engineers to design thin and lightweight structures characterized by a high load-bearing capacity. The main advantages of this material are related to its durability and strength performance, since no cover against corrosion is required, while it is also possible to align

\author{
M. Colombo \\ e-mail: matteo.colombo@polimi.it \\ M. di Prisco \\ e-mail: marco.diprisco@polimi.it
}


fibres along the load direction. In particular, thanks to the bi-dimensionality of the fabrics, a bi-axial load can be supported easily by such a reinforced structure. During the last 10 years, the scientific community's growing interest in the technology has been demonstrated by the establishment of several research projects, the majority in Germany, Israel and the USA.

In the last few years a research project focussing on TRC was also set up at the Politecnico di Milano, in Italy; the main results achieved by this project form the basis of the present paper.

As a composite material, the strength of TRC depends not only on that of its components, but also on the bond between reinforcement and matrix. Analysis of this bond is thus one of the main topics in TRC studies. The bond can be affected by many factors, such as curing conditions and pressure applied after laminate casting [1], fabrication technique [2], fibre type and treatment of fibre surface [3]. To study this phenomenon, pull-out tests have been performed and numerous models developed [4-6].

Durability is another key issue for composite materials. A number of researchers have developed durability models to quantify strength loss in textile reinforced composites resulting from AR-glass degradation problems and weathering conditions (humidity and temperature) $[7,8]$. Others have focused on the effect of matrix composition (hydration kinetics and alkalinity) on TRC durability [9], observing that an alkali reduced matrix exhibits strong performance even if exposed to accelerated ageing. The decrease in toughness with increasing alkalinity depends mainly on the formation of solid phases in the fabric-matrix interface, rather than on deterioration of the AR glass fabric.

A research project is currently in progress at the Politecnico di Milano involving the investigation of situations in which TRC is mainly subjected to tensile load. The following applications in particular are being taken into account: retrofitting of damaged structures, façades, precast multi-layered roof panels and tunnel linings.

This paper presents the main results of the experimental campaign and tries to answer to some very important questions raised by TRC users:

1) How do fabric geometry, position and reinforcement ratio affect the tensile behaviour of the composite?

2) Does composite curing method affect the final tensile behaviour of TRC?
Table 1 Mix design $w /(c+s)=0.19$

\begin{tabular}{ll}
\hline Component & Content \\
\hline Cement I 52.5 & $600 \mathrm{~kg} / \mathrm{m}^{3}$ \\
Sand $0-600 \mu \mathrm{m}$ & $957 \mathrm{~kg} / \mathrm{m}^{3}$ \\
Water & $2091 / \mathrm{m}^{3}$ \\
Superplasticizer & $44^{\mathrm{a}}-56^{\mathrm{b}} \mathrm{kg} / \mathrm{m}^{3}$ \\
Slag & $500 \mathrm{~kg} / \mathrm{m}^{3}$ \\
\hline
\end{tabular}

a Specimens reinforced with fabric F1

b Specimens reinforced with fabric F2-F3-DS

3) Does strain rate play a key role in the definition of ductility and strength in uniaxial tensile behaviour?

4) TRC experiences a multicrack pattern and even global hardening response in some cases: is this size-effect dependent?

\section{Research significance}

The experimental results presented here, obtained as part of a research investigation carried out at the Politecnico di Milano, aim to highlight the performance of a composite material, generally known as Textile Reinforced Concrete, for use in precast structures. The results represent a useful tool with which architects and engineers can understand the geometric, technological and mechanical parameter sensitivity of the standard uniaxial tensile behaviour of TRC, as well as how this behaviour is affected by different factors.

\section{Materials and experimental set-up}

TRC specimens tested during the experimental investigation were created by reinforcing a high strength

Table 2 Bending, tensile and compressive strength-specimens reinforced with fabric F1 (superplasticizer $44 \mathrm{~kg} / \mathrm{m}^{3}$ )

\begin{tabular}{llccrl}
\hline Specimen & Batch & $f_{\text {ctf }}(\mathrm{MPa})$ & $f_{\text {ctm }}(\mathrm{MPa})$ & \multicolumn{3}{c}{$f_{\text {cc }}(\mathrm{MPa})$} \\
\hline $\mathrm{N} 1$ & 1 & 14.98 & 6.63 & 114.81 & 103.60 \\
$\mathrm{~N} 2$ & 1 & 16.97 & 7.51 & 106.38 & 126.68 \\
N3 & 1 & 17.86 & 7.90 & 107.03 & 107.63 \\
N4 & 2 & 19.51 & 8.63 & 99.74 & 108.53 \\
N5 & 2 & 19.15 & 8.47 & 114.33 & 113.05 \\
N6 & 2 & 20.72 & 9.17 & 114.71 & 121.11 \\
Average & & 18.20 & 8.05 & 111.46 & \\
STD & & 2.05 & 0.91 & 7.54 & \\
STD\% & & 11.25 & 11.25 & 6.76 & \\
\hline
\end{tabular}


Table 3 Bending, tensile and compressive strength-specimens reinforced with fabrics F2 and F3 (superplasticizer $56 \mathrm{~kg}$ / $\left.\mathrm{m}^{3}, \mathrm{DS}\right)$

\begin{tabular}{llllrr}
\hline Specimen & Batch & $f_{\text {ctf }}(\mathrm{MPa})$ & $f_{\text {ctm }}(\mathrm{MPa})$ & \multicolumn{3}{c}{$f_{\text {cc }}(\mathrm{MPa})$} \\
\hline $\mathrm{N} 1$ & 4 & 13.82 & 6.10 & 98.69 & 114.29 \\
$\mathrm{~N} 2$ & 4 & 17.45 & 7.70 & 103.23 & 107.47 \\
$\mathrm{~N} 3$ & 5 & 11.76 & 5.20 & 94.90 & 92.38 \\
$\mathrm{~N} 4$ & 5 & 12.32 & 5.45 & 97.92 & 80.34 \\
$\mathrm{~N} 5$ & 5 & 13.58 & 6.00 & 94.22 & 94.86 \\
$\mathrm{~N} 6$ & 6 & 13.65 & 6.03 & 103.26 & 95.79 \\
$\mathrm{~N} 7$ & 6 & 12.72 & 5.63 & 92.39 & 93.01 \\
N8 & 6 & 13.62 & 6.02 & 97.43 & 100.55 \\
Average & & 13.62 & 6.02 & 97.54 & \\
STD & & 1.72 & 0.76 & 7.54 & \\
STD\% & & 12.62 & 12.62 & 7.73 & \\
\hline
\end{tabular}

concrete with different layers of AR glass fabric. Three types of fabric (named F1, F2 and F3) were used as reinforcement. The material properties and experimental set-up are described below.

\subsection{Matrix}

A high strength concrete, characterized by a water to binder ratio of 0.19 and a maximum grain size of $600 \mu \mathrm{m}$, was used to cast the TRC specimens. The matrix mix design is summarized in Table 1.

The maximum aggregate size and superplasticizer addition were designed to allow the matrix to flow through the mesh of the fabric; a high flowing capability should guarantee a good bond between fabric and concrete. In addition, superplasticizer content was increased from $44 \mathrm{~kg} / \mathrm{m}^{3}$ (used in case of reinforcement $\mathrm{F} 1$ ) to $56 \mathrm{~kg} / \mathrm{m}^{3}$ (F2 and F3) in order to improve concrete workability, since dry sand (DS) was included in the recipe involving the latter two fabric types. A low relative humidity was obtained by keeping this sand in an oven for half an hour before manufacturing the specimens. Following the European Standard for cement testing (UNI EN 196-1 [10]), bending and compressive tests were carried out on prismatic specimens in order to quantify the mechanical properties of the matrix; Tables 2 and 3 display the bending tensile strength $\left(f_{\text {ctf }}\right)$, tensile strength $\left(f_{\text {ctm }}\right)$ and cubic compressive strength $\left(f_{\text {cc }}\right)$ for both mix designs.

Tensile strength was deduced from the bending tensile strength via the formula proposed in the Model Code [11]:
$f_{\mathrm{ctm}}=A_{\mathrm{fl} l} \cdot f_{\mathrm{ctf}} \quad A_{\mathrm{fl}}=\frac{a_{\mathrm{fl}} \cdot h_{\mathrm{b}}^{0.7}}{1+a_{\mathrm{fl}} \cdot h_{\mathrm{b}}^{0.7}}$

where $h_{b}$ is beam depth, equal to $40 \mathrm{~mm}$, and $\alpha_{\mathrm{fl}}$ is a coefficient that decreases with increasing concrete brittleness. This coefficient was considered here to be equal to 0.06 as suggested for normal strength concrete; however, for high strength concrete such as the one used in the present study, its value is expected to be lower.

The tensile strength $f_{\mathrm{ctm}}$ of batch 6 as deduced from the bending test (Table 3) was compared with the strength value obtained by testing, in direct tension, $400 \times 70 \times 6 \mathrm{~mm}$ plain concrete specimens cast in the same batch; these specimens had the same dimensions as the tested TRC samples.

Through indirect measurement, the average value, obtained as discussed before $\left(\alpha_{\mathrm{fl}}=0.06\right)$, was found to be equal to $6.02 \mathrm{MPa}$. In contrast, direct measurement resulted in a value of $4.77 \mathrm{MPa}$, albeit with greater scatter $(22 \%)$. These results justify the necessity of employing a lower value of $\alpha_{\mathrm{fl}}$, as suggested in the Model Code; a value of $\alpha_{\mathrm{fl}}$ equal to 0.04 should provide a reliable prediction of tensile strength.

Table 3 reveals that the inclusion of dry sand resulted in a decrease in material strength of about $25 \%$ for tension and $12 \%$ for compression. This is probably related to the low water to binder ratio in which not all the cement is hydrated.

\subsection{Fabric}

Three different fabrics (F1, F2 and F3) were used to reinforce the TRC specimens (Fig. 1). The geometric properties of each fabric are summarized in Table 4. The choice of these three fabrics was made after performing several investigations aimed at optimizing performance in terms of the ductility of the composite material, the bond between matrix and fabric, and internal filament slip. The variables considered in the preliminary study were fabric geometry (warp and weft spacing and their cross-section), fabric weaving and fabric coating, with the ultimate aim being to achieve maximum TRC strength and ductility.

The best results were obtained using tight warp and weft spacing, the leno weave fabrication technique and a coated (rather than uncoated) fabric.

For each kind of reinforcement considered, ten uniaxial tensile tests were performed in order to characterize fabric tensile behaviour. These tensile tests 
Fig. 1 Uniaxial tension test results: load versus displacement average curves for fabrics F1, F2 and F3

Table 4 Geometric characteristics of fabrics

a Average value of 10 tensile tests

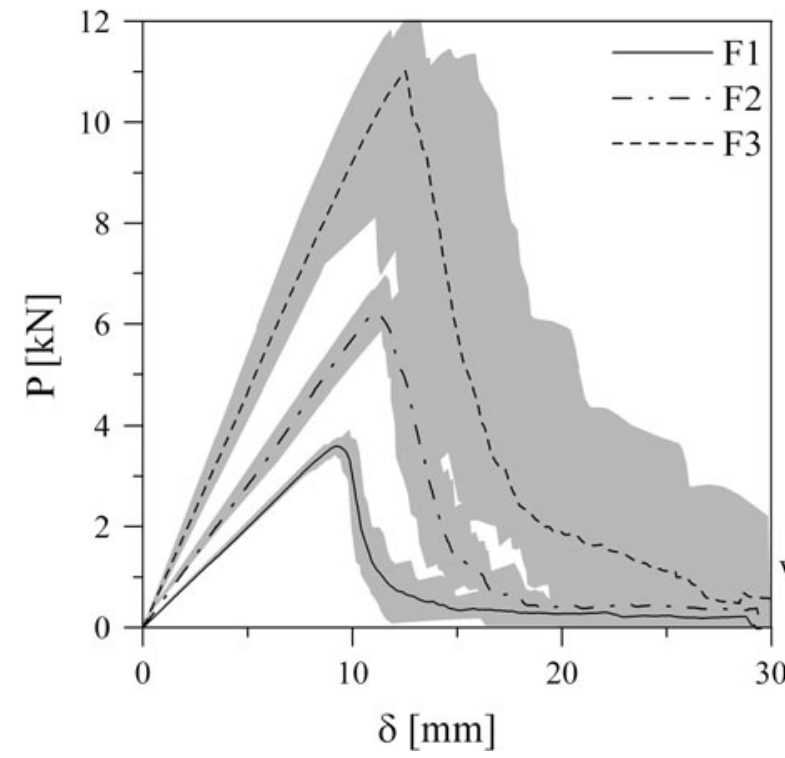

fabric F1 (16 warp wires)

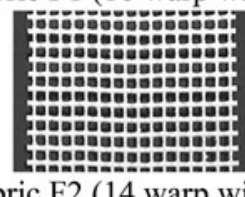

fabric F2 (14 warp wires)

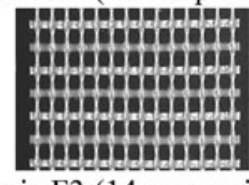

fabric F3 (14 warp wires)

warp

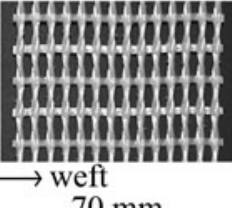

$70 \mathrm{~mm}$

\begin{tabular}{llll}
\hline & F1 & F2 & F3 \\
\hline Material & AR-glass & AR-glass & AR-glass \\
Fabrication technique & Leno weave & Leno weave & Leno weave \\
Warp wire spacing $(\mathrm{mm})$ & 4.4 & 4.9 & 4.9 \\
Weft wire spacing $(\mathrm{mm})$ & 5.0 & 7.1 & 10.1 \\
Warp (Tex) & $2 \times 320$ & $2 \times 640$ & $2 \times 1200$ \\
Weft $($ Tex $)$ & 640 & 1200 & 1200 \\
Warp filament $(\mu \mathrm{m})$ & 14 & 14 & 19 \\
Weft filament $(\mu \mathrm{m})$ & 14 & 19 & 19 \\
Maximum tensile load on $70 \mathrm{~mm}(\mathrm{kN})^{\mathrm{a}}$ & 3.67 & 6.58 & 11.02 \\
\hline
\end{tabular}

were carried out using an INSTRON 5867 electromechanical press with a maximum load capacity of $30 \mathrm{kN}$. Specimens $400 \times 70 \mathrm{~mm}^{2}$ in size were clamped to the machine, with five layers of adhesive paper tape applied to the upper and lower ends of each sample to prevent slip between clamps and fabric. The pressure applied to the pneumatic clamps was equal to $5.8 \mathrm{MPa}$ for fabric $\mathrm{F} 1$ and F2 and 8.5 MPa for fabric F3. The tests were displacement-controlled by imposing a constant stroke rate of $100 \mathrm{~mm} / \mathrm{min}$. Load-displacement curves are shown in Fig. 1, while the maximum tensile load achieved by each fabric is indicated in Table 5 .

Nominal stress was calculated by dividing the maximum tensile load by the nominal area of warp roving (considering the amount of warp roving in each fabric). The nominal strengths for each fabric were respectively equal to $896 \mathrm{MPa}$ for F1, $918 \mathrm{MPa}$ for F2
Table 5 Fabric maximum tensile load $(\mathrm{kN})$

\begin{tabular}{lllr}
\hline & F1 & F2 & \multicolumn{1}{c}{ F3 } \\
\hline N1 & 3.65 & 6.91 & 11.85 \\
N2 & 3.44 & 6.45 & 10.97 \\
N3 & 3.91 & 6.12 & 9.83 \\
N4 & 3.78 & 6.77 & 11.04 \\
N5 & 3.81 & 6.31 & 12.26 \\
N6 & 3.68 & 6.58 & 10.27 \\
N7 & 3.83 & 6.58 & 10.61 \\
N8 & 3.58 & 6.71 & 10.92 \\
N9 & 3.61 & 6.39 & 10.94 \\
N10 & 3.47 & 6.97 & 11.50 \\
Average maximum tensile load & 3.67 & 6.58 & 11.02 \\
on 70 mm & & & \\
STD & 0.16 & 0.27 & 0.72 \\
STD\% & 4.25 & 4.09 & 6.52 \\
\hline
\end{tabular}


and $820 \mathrm{MPa}$ for F3. The huge scattering observed in Fig. 1, with reference to fabric F3, is mainly dependent on the relatively reduced clamping pressure when compared to the peak load measured. A possible sliding could affect the peak strain and therefore can be regarded as the main responsible for the quite high dispersion in the softening regime.

According to Curbach and Jesse [12], the tensile strength of a filament with diameter $13.5 \mu \mathrm{m}$ (used in 310 and 620 tex yarn) is about $2300 \mathrm{MPa}$, whereas the strength of the corresponding yarn is about $1400 \mathrm{MPa}$, representing a loss of about $40 \%$. In contrast, the loss in strength realized when using a filament with diameter $16.0 \mu \mathrm{m}$ (used in 1100 tex yarn) is about $70 \%$, from 2100 to $600 \mathrm{MPa}$. Possible reasons for this, according to Curbach and Jesse, are the non-uniform distribution of the load between the filaments inside the yarn and the presence of defects. In the present study, a loss in strength of about 55-60\% was computed both for $14 \mu \mathrm{m}$ diameter filaments of fabrics F1 and F2, and for $19 \mu \mathrm{m}$ filaments of fabric F3, with respect to the filament strength obtained by linear interpolation from the results of Curbach and Jesse $(14 \mu \mathrm{m}$ : $2260 \mathrm{MPa}$ and $19 \mu \mathrm{m}$ : $1912 \mathrm{MPa})$. For the lower filament diameter, the strength loss was higher than that observed by Curbach and Jesse. This could be due to a structural effect in fabric manufacture during which filaments are weaved and twisted, thus leading to possible damage.

\subsection{Specimen preparation}

The method of manufacture employed to produce the specimens was the hand lay-up technique, which is characterized by the exertion of a negligible pressure during production. A proper formwork with a transparent bottom plate was used in order to check by visible inspection the penetration of the matrix into the fabric mesh. A number of overlapping steel rails were also used as separation layers in-between the different textile layers (Fig. 2b). A suitable amount of concrete was spread onto the formwork bottom plate and smoothed with a roller to remove any air bubbles, with the reinforcement positioned tight and fixed at the edges. This procedure was then repeated to create a multilayer specimen. The specimens used in the experimental investigation were reinforced in three different ways, as shown in Fig. 3:

- one single fabric between two concrete layers;

- two fabrics (in direct contact with each other) between concrete;

- two single fabric layers divided by a $2 \mathrm{~mm}$-thick layer of concrete.

In all cases the warp was parallel to the long side of the specimen.

The obtained specimens were $400 \mathrm{~mm}$ long, $70 \mathrm{~mm}$ wide and $6 \mathrm{~mm}$ thick, with at least three nominally identical specimens manufactured for each test.

The employed hand laminating technique is shown in Fig. 2a, while specimen geometry and reinforcement layout are shown in Fig. 3.

After 1 day in a climate chamber at $98 \% \mathrm{RH}$, specimens were demoulded and cured in a wet environment $(\mathrm{RH}>98 \%$ ) for 28 days until being tested. Keeping the specimens in this wet environment ensured the avoidance of any loss in planarity arising from non-uniform shrinkage.

\subsection{Test set-up}

TRC specimens were tested using the same electromechanical press employed for the fabric tensile tests (Fig. 4). A pressure ranging between 3.9 and $5.6 \mathrm{MPa}$ was applied to clamp the specimen edges, while $3 \mathrm{~mm}$ (a)

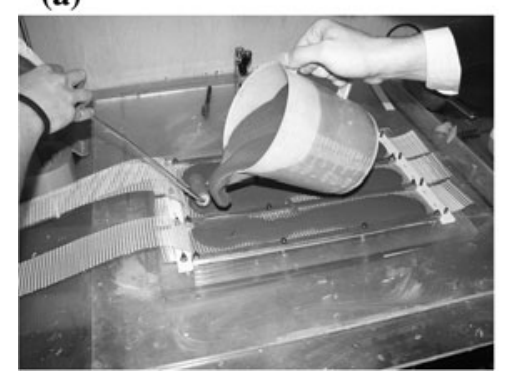

(b)

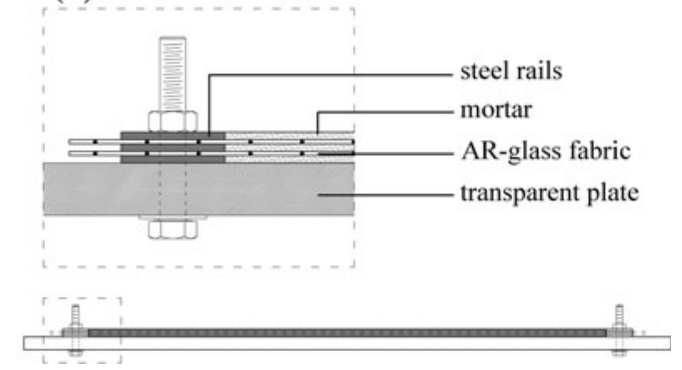

Fig. 2 Specimen preparation (a) and section of the specimen in the formwork (b) 
Fig. 3 Specimen geometry and reinforcement layout (measurements in $\mathrm{mm}$; measurements in brackets refer to perspex plate solution)

Fig. 4 Tensile test set-up
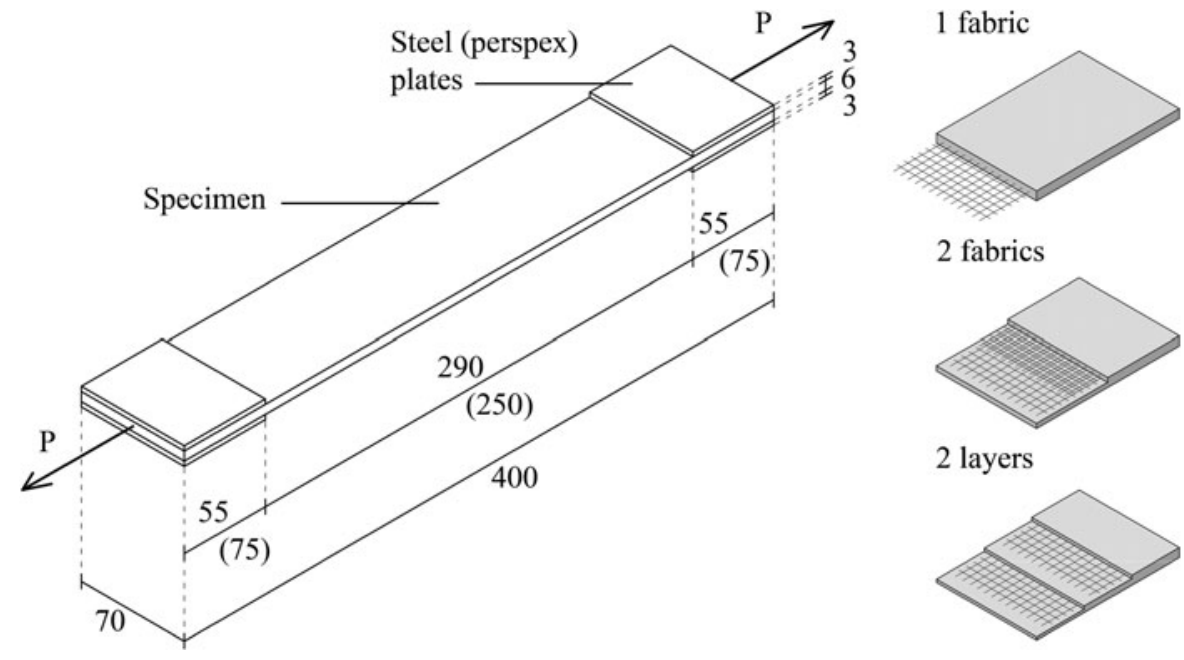

2 fabrics

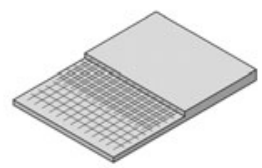

2 layers

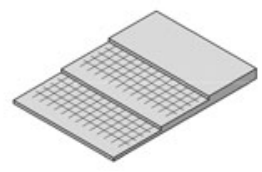

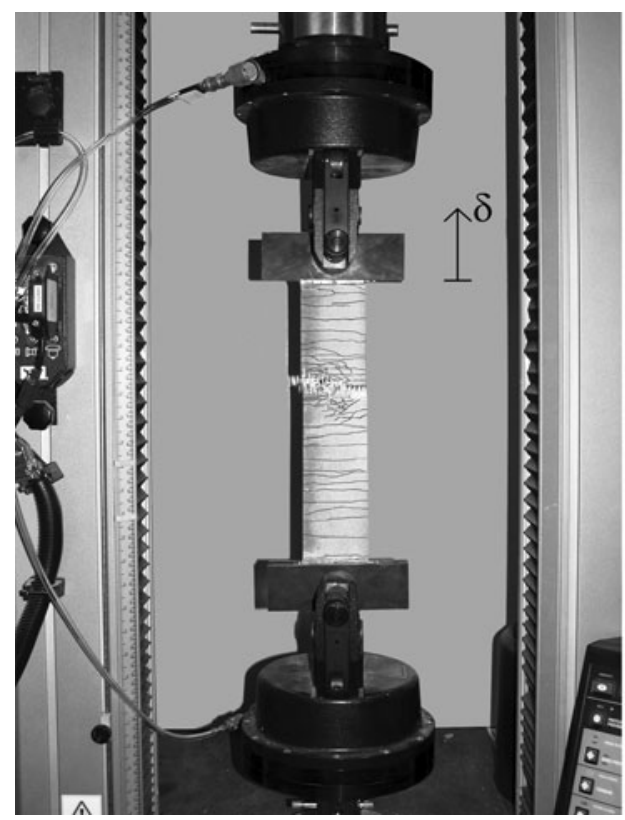

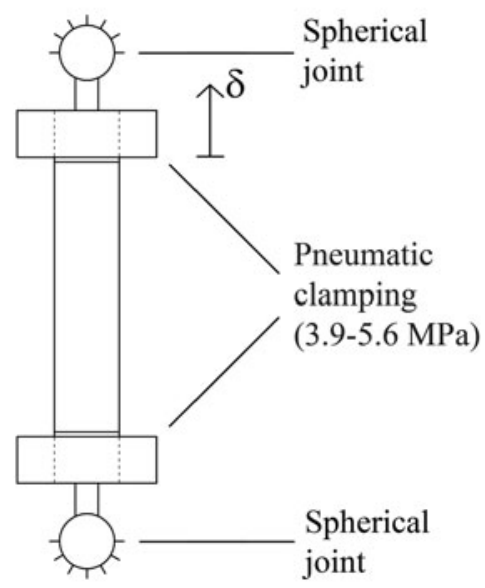

thick plates were glued to the surface of the specimen at the grips to better distribute the clamping pressure and thus minimize damage associated with local crushing; $75 \times 70 \mathrm{~mm}$ perspex plates were used with $\mathrm{F} 1$, and $55 \times 70 \mathrm{~mm}$ steel plates were used with F2 and F3. To prevent torsional and bending moments caused by misalignment of the constraints, spherical joints were placed at the ends. Spherical joints were always used for F1 specimens because the peak load never surpassed $8 \mathrm{kN}$ (ultimate load of the joints). For higher peak loads the specimens could use only backlashes of the clamping devices, thus preventing precise detection of first cracking strength.

The tests were displacement-controlled by imposing a constant stroke rate of $0.02 \mathrm{~mm} / \mathrm{s}$. In terms of clamping, according to Harting et al. [13], this type of set-up involving glued steel plates can be classified as "rigid load application": concrete cracking is prevented within the supported range, while the main transfer mechanism between specimen and clamping device is adhesive tension and shear. On the contrary, in terms of displacements allowed at the ends, it might 
be classified as a rotating end uniaxial tension apparatus.

\section{Tensile behaviour of TRC}

Load bearing behaviour was evaluated through direct tension tests. As previously schematized by Hegger et al. [14], the produced non-linear stress versus strain curve (Fig. 5) can be divided into three sections.

In the first linear branch (I, Fig. 5), the material is uncracked and the slope reflects the elastic modulus of the concrete. The contribution to stiffness offered by the reinforcement is negligible according to Ohno and Hannant [15]. Once the tensile strength of the matrix is reached, the whole force is transferred through the crack to the fabric (IIa). Thanks to the bond between textile and concrete, the reinforcement redistributes the load until the tensile strength of the matrix is reached in another section of the specimen, thus creating a new crack. Repetition of this process results in the formation of a multicrack pattern along the specimen, the distance and width of which are strictly related to fabric geometry and to the bond between reinforcement and concrete. In Fig. 5, multicracking occurs in the branch defined by a fairly constant load, with an increase in the total equivalent strain taking place due to multiple crack formation. Increasing the deformation, only the contribution of the fabric (IIb) is noticeable, with no further cracks appearing and the fabric strained upwards.

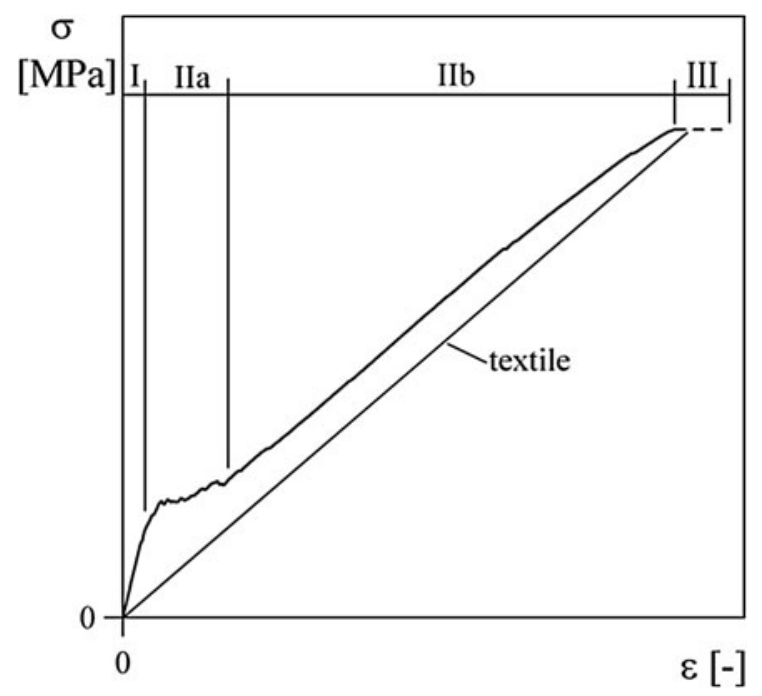

Fig. 5 Tensile behaviour of textile reinforced concrete, stress versus strain curve
Table 6 Nominal reinforcement ratio for fabrics F1, F2 and F3

\begin{tabular}{llll}
\hline Fabric & 1 fabric $(\%)$ & 2 fabrics $(\%)$ & 2 layers $(\%)$ \\
\hline F1 & 0.97 & 1.94 & 1.94 \\
F2 & 1.71 & 3.42 & 3.42 \\
F3 & 3.20 & - & - \\
\hline
\end{tabular}

Figure 5 also presents a comparison of the behaviour of the fabric with that of TRC; the difference between the two curves is due to the tension stiffening effect. The final state is defined by the failure of the AR glass fabric when the textile reaches ultimate strain (III). The occurrence of this event depends on a series of parameters such as nature of fibre, fabric geometry, reinforcement ratio and bond phenomena. Since AR glass is characterized by brittle failure without any plastic deformation, the type of TRC employed in the present study does not experience the final plateau indicated by the dashed line (Fig. 5).

Several design parameters were investigated in order to define their influence on this behaviour, as well as their effect on the different stages of tensile response. In particular, the following parameters are discussed:

a) Reinforcement amount and position

b) Fabric geometry

c) Composite curing procedure

d) Strain rate

e) Size effect.

\subsection{Effect of reinforcement amount and position}

The equivalent section area of reinforcement $\left(A_{\mathrm{f}}\right)$ was computed from the Tex of each single roving, the number $(n)$ of rovings across specimen width (16 for $\mathrm{F} 1$ and 14 for both F2 and F3) and the AR-glass density $(\rho)$ :

$A_{f}=n \frac{T e x}{\rho}$

In the case of fabrics $\mathrm{F} 1$ and $\mathrm{F} 2$, different geometric reinforcement ratios $\left(A_{\mathrm{f}} / A_{\mathrm{c}}\right.$ where $A_{\mathrm{c}}$ is specimen cross-section) were achieved by employing different fabric layer configurations across specimen thickness; the values considered are summarized in Table 6 . In this table, the terms "1 fabric", "2 fabrics" and "2 layers" correspond to the three reinforcement configurations outlined in Sect. 2.3 and Fig. 3. 
Fig. 6 TRC reinforced with fabric F1. Nominal stress versus normalized displacement curves in uniaxial tension (a) and specimen cracking pattern (b)

Fig. 7 TRC reinforced with fabric F2. Nominal stress versus normalized displacement curves in uniaxial tension (a) and specimen cracking pattern (b)
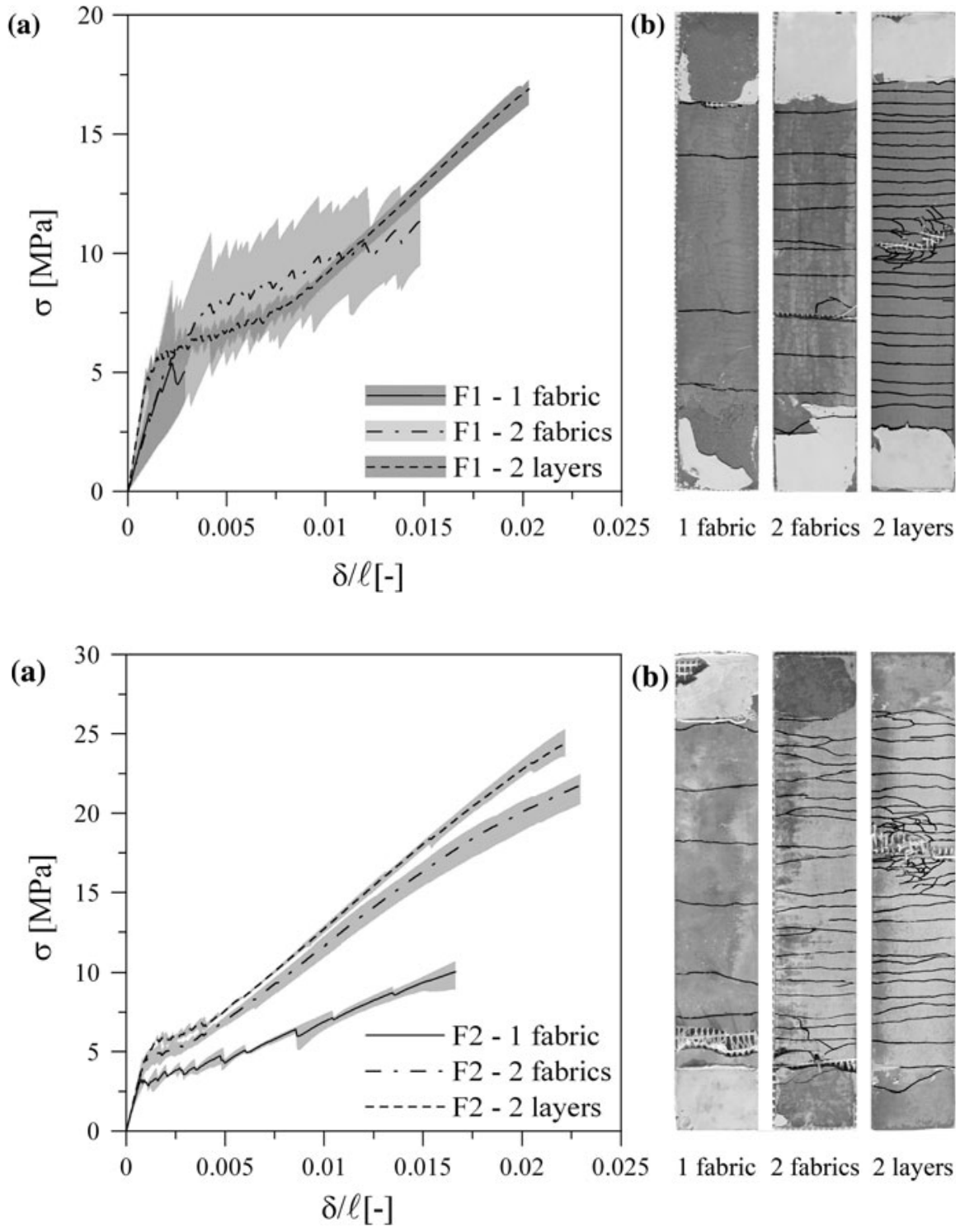

(b)
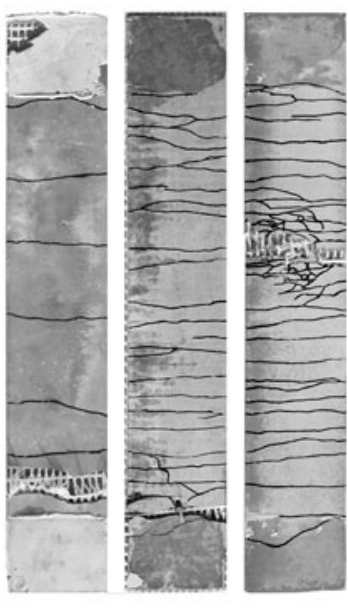

1 fabric 2 fabrics 2 layers
The results of tensile tests for the different fabric types and configurations investigated are shown in Figs. 6, 7 and 8 by means of nominal stress $(\sigma)$ versus normalized displacement $(\delta / 1)$ curves, while the corresponding numerical data values are collected in Tables 7,8 and 9 , respectively (with reference to $10 \mathrm{~mm}$ weft spacing). Nominal stress was obtained by dividing the load by specimen cross-section area, whereas normalized displacement was calculated as the applied stroke displacement $(\delta)$ divided by the initial distance between clamping edges. It is worth noting that each average curve in every graph is interrupted when the first of the three nominally identical specimens reaches the ultimate normalized displacement; as a result, the peak of the average curve differs from the average peak value (shown in the corresponding table).

For each configuration the average curve of 3 nominally identical tests is shown together with a shadowed area representing result scatter, while typical cracking patterns are displayed to the right.

In the case of the F1-1 fabric test (Fig. 6), the second and third branches typically seen in TRC multi-cracking behaviour are absent. Analysis of the cracking pattern reveals that just a few cracks appeared in the specimen; this is likely the result of 
Fig. 8 Comparison between TRC reinforced with fabric F2-2 layers and fabric F3-1 fabric (similar $\left.\rho_{\mathrm{f}}\right)$. Nominal stress versus normalized displacement curves in uniaxial tension (a) and specimen cracking pattern (b)

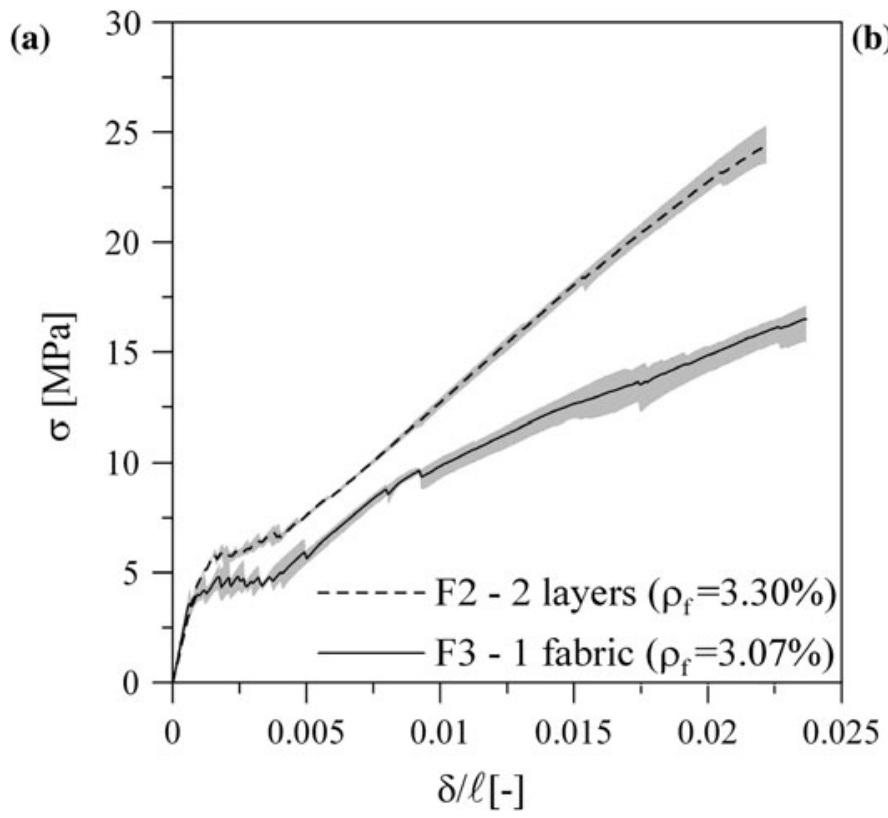

(b)
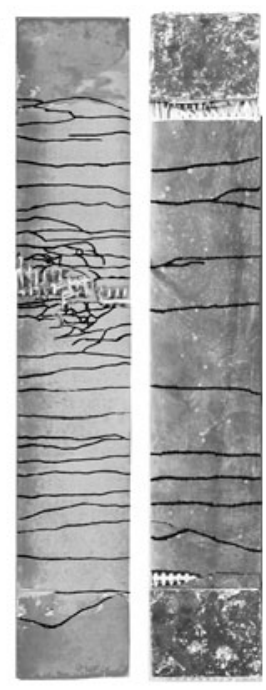

F2

F3

2 layers 1 fabric a release of energy at the onset of cracking that was too large to allow stress redistribution between concrete and reinforcement, thus causing the failure of the composite itself. This situation is similar to that occurring in an $\mathrm{R} / \mathrm{C}$ section characterized by minimum reinforcement endowed by negligible ductility.

In the F1-2 fabrics scenario, bond failure prevented the onset of stage IIb despite the increase in total reinforcement, resulting in progressive sliding of the fabric as highlighted by the longer IIa branch.

For F1-2 layers, typical TRC behaviour was achieved, with a very dense cracking pattern exhibited.

The same behaviour is evident in Fig. 7 for both F22 fabrics and F2-2 layers. The solutions have the same reinforcement ratio and experience a similar cracking pattern and ultimate strain. However, the use of 2 layers resulted in a higher tensile strength due to the better bond guaranteed by the concrete layer between the two fabrics.

When two fabrics are in contact, the area of the matrix-fabric interface decreases and sliding takes place. Bonding thus has a significant effect on the composite material, determining both its strength and ductility. As with every composite material, the load-bearing capacity is strictly connected to the bond behaviour of the reinforcing material, with weak and strong bonds associated with ductile to brittle behaviour, respectively. In the case of TRCs, bond behaviour is quite different to that observed in steel reinforcement due to the inhomogeneity of the fibre cross-section. The bond between steel bar and matrix in $\mathrm{R} / \mathrm{C}$ is governed by several mechanisms, including adhesion, which is lost
Fig. 9 Idealization of a yarn embedded in the matrix [16]

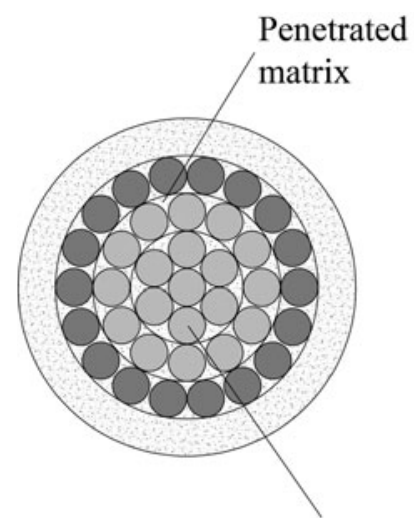

Matrix
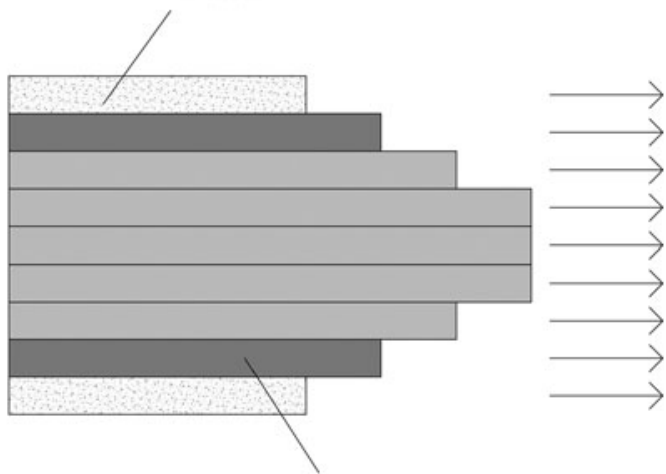

Core filaments
Sleeve filaments 
Table 7 Test results for specimens reinforced with fabric F1

\begin{tabular}{|c|c|c|c|c|c|c|c|c|c|}
\hline & Specimen & Batch & $t(\mathrm{~mm})$ & $P_{\max }(\mathrm{kN})$ & $\delta_{\mathrm{u}}(\mathrm{mm})$ & $\sigma_{\max }(\mathrm{MPa})$ & $\delta_{\mathrm{u}} / 1(-)$ & $\sigma_{\mathrm{I}}(\mathrm{MPa})$ & $\mathrm{EF}(-)$ \\
\hline \multirow[t]{8}{*}{ F1-1 fabric } & N1 & 7 & 6.9 & 3.75 & 0.59 & 7.76 & 0.0024 & 7.76 & 1.02 \\
\hline & $\mathrm{N} 2$ & 7 & 6.7 & 4.17 & 0.56 & 8.90 & 0.0022 & 8.90 & 1.14 \\
\hline & N3 & 7 & 6.9 & 4.13 & 1.12 & 8.55 & 0.0046 & 5.55 & 1.12 \\
\hline & N4 & 1 & 6.7 & 3.55 & 2.02 & 7.56 & 0.0081 & 5.13 & 0.97 \\
\hline & N5 & 1 & 6.7 & 3.37 & 2.65 & 7.19 & 0.0107 & 5.18 & 0.92 \\
\hline & N6 & 1 & 6.8 & 3.87 & 4.92 & 8.14 & 0.0199 & 3.00 & 0.84 \\
\hline & Average & & 6.8 & 3.81 & 1.98 & 8.02 & 0.0080 & 5.92 & 1.00 \\
\hline & s.d. & & 0.10 & 0.32 & 1.66 & 0.64 & 0.0067 & 2.10 & 0.12 \\
\hline \multirow[t]{8}{*}{ F1-2 fabrics } & N1 & 7 & 7.1 & 6.56 & 4.35 & 13.19 & 0.0174 & 8.30 & 0.89 \\
\hline & $\mathrm{N} 2$ & 7 & 7.1 & 6.50 & 3.73 & 13.07 & 0.0148 & 8.40 & 0.89 \\
\hline & N3 & 7 & 7.2 & 6.91 & 4.77 & 13.71 & 0.0195 & 6.03 & 0.94 \\
\hline & N4 & 1 & 7.2 & 7.35 & 6.65 & 14.58 & 0.0268 & 5.06 & 1.00 \\
\hline & N5 & 1 & 7.3 & 6.56 & 6.22 & 12.84 & 0.0253 & 4.17 & 0.89 \\
\hline & N6 & 1 & 6.7 & 6.42 & 5.41 & 13.69 & 0.0220 & 6.41 & 0.87 \\
\hline & Average & & 7.1 & 6.72 & 5.19 & 13.52 & 0.0210 & 6.40 & 0.91 \\
\hline & s.d. & & 0.21 & 0.35 & 1.12 & 0.63 & 0.0046 & 1.70 & 0.05 \\
\hline \multirow[t]{8}{*}{ F1-2 layers } & N1 & 2 & 6.3 & 8.44 & 6.73 & 19.14 & 0.0234 & 4.23 & 1.15 \\
\hline & $\mathrm{N} 2$ & 2 & 6.2 & 8.39 & 6.77 & 19.33 & 0.0235 & 2.93 & 1.14 \\
\hline & N3 & 2 & 6.3 & 7.49 & 5.89 & 16.99 & 0.0204 & 4.42 & 1.02 \\
\hline & N4 & 3 & 6.5 & 7.67 & 6.30 & 17.52 & 0.0218 & 5.25 & 1.04 \\
\hline & N5 & 3 & 6.2 & 7.48 & 6.00 & 17.24 & 0.0208 & 5.80 & 1.02 \\
\hline & N6 & 3 & 6.5 & 7.78 & 6.27 & 17.08 & 0.0218 & 4.79 & 1.06 \\
\hline & Average & & 6.3 & 7.92 & 6.33 & 17.88 & 0.0219 & 4.57 & 1.07 \\
\hline & s.d. & & 0.14 & 0.43 & 0.36 & 1.06 & 0.0013 & 0.99 & 0.06 \\
\hline
\end{tabular}

$t$ thickness, $P_{\max }$ peak load, $\delta_{\mathrm{u}}$ displacement at the peak load, $\sigma_{\max }$ peak stress, $\delta_{\mathrm{u}} / 1$ normalized displacement at the peak stress, $\sigma_{\mathrm{I}}$ first cracking stress, $E F$ efficiency factor

Table 8 Test results for specimens reinforced with fabric F2

\begin{tabular}{llllllllll}
\hline & Specimen & Batch & $t(\mathrm{~mm})$ & $P_{\max }(\mathrm{kN})$ & $\delta_{\mathrm{u}}(\mathrm{mm})$ & $\sigma_{\max }(\mathrm{MPa})$ & $\delta_{\mathrm{u}} / \mathrm{l}(-)$ & $\sigma_{\mathrm{I}}(\mathrm{MPa})$ & $\mathrm{EF}(-)$ \\
\hline F2-1 fabric & $\mathrm{N} 1$ & 8 & 6.0 & 5.63 & 6.28 & 13.39 & 0.0219 & 4.20 & 0.86 \\
& $\mathrm{~N} 2$ & 8 & 6.5 & 4.07 & 4.85 & 8.94 & 0.0168 & 3.19 & 0.62 \\
& $\mathrm{~N} 3$ & 8 & 6.5 & 5.35 & 5.60 & 11.76 & 0.0193 & 3.01 & 0.81 \\
& Average & & 6.3 & 5.02 & 5.57 & 11.36 & 0.0193 & 3.47 & 0.76 \\
F2-2 fabrics & N1 & 9 & 7.3 & 11.05 & 7.43 & 21.62 & 0.0257 & 3.81 & 0.84 \\
& N2 & 9 & 6.8 & 11.07 & 7.15 & 23.26 & 000247 & 4.63 & 0.84 \\
& N3 & 9 & 6.9 & 10.74 & 6.66 & 22.25 & 0.0230 & 4.99 & 0.82 \\
& Average & & 7.0 & 10.95 & 7.08 & 22.37 & 0.0245 & 4.48 & 0.83 \\
& N1 & 9 & 6.5 & 10.72 & 6.39 & 23.57 & 0.0222 & 4.69 & 0.81 \\
& N2 & 9 & 6.1 & 10.86 & 6.49 & 25.42 & 0.0225 & 3.91 & 0.83 \\
& N3 & 9 & 6.1 & 10.37 & 6.47 & 24.28 & 0.0224 & 5.27 & 0.79 \\
& Average & & 6.2 & 10.65 & 6.45 & 24.42 & 0.0224 & 4.62 & 0.81 \\
\hline
\end{tabular}


Table 9 Test results for specimens reinforced with fabric F3-1 fabric (weft spacing varied)

\begin{tabular}{|c|c|c|c|c|c|c|c|c|c|}
\hline & Specimen & Batch & $t(\mathrm{~mm})$ & $P_{\max }(\mathrm{kN})$ & $\delta_{\mathrm{u}}(\mathrm{mm})$ & $\sigma_{\max }(\mathrm{MPa})$ & $\delta_{\mathrm{u}} / 1(-)$ & $\sigma_{\mathrm{I}}(\mathrm{MPa})$ & $\mathrm{EF}(-)$ \\
\hline \multirow[t]{4}{*}{$10 \mathrm{~mm}$} & N1 & 10 & 6.2 & 7.86 & 7.80 & 17.97 & 0.0270 & 3.48 & 0.71 \\
\hline & $\mathrm{N} 2$ & 10 & 6.3 & 7.32 & 7.66 & 16.45 & 0.0265 & 4.36 & 0.66 \\
\hline & N3 & 10 & 6.1 & 7.35 & 6.85 & 16.97 & 0.0237 & 4.26 & 0.67 \\
\hline & Average & & 6.2 & 7.51 & 7.44 & 17.13 & 0.0257 & 4.03 & 0.68 \\
\hline \multirow[t]{3}{*}{$20 \mathrm{~mm}$} & N1 & 11 & 6.8 & 7.31 & 4.50 & 15.34 & 0.0156 & 5.82 & 0.66 \\
\hline & $\mathrm{N} 2$ & 11 & 6.7 & 7.40 & 4.78 & 15.67 & 0.0166 & 5.09 & 0.67 \\
\hline & Average & & 6.8 & 7.36 & 4.64 & 15.51 & 0.0161 & 5.46 & 0.67 \\
\hline \multirow[t]{4}{*}{$30 \mathrm{~mm}$} & N1 & 11 & 6.0 & 8.19 & 5.36 & 19.55 & 0.0186 & 7.43 & 0.74 \\
\hline & N2 & 11 & 6.3 & 7.43 & 4.78 & 16.62 & 0.0165 & 6.99 & 0.67 \\
\hline & N3 & 11 & 6.5 & 7.18 & 4.43 & 15.87 & 0.0153 & 8.74 & 0.65 \\
\hline & Average & & 6.3 & 7.60 & 4.86 & 17.35 & 0.0168 & 7.72 & 0.69 \\
\hline \multirow[t]{4}{*}{$50 \mathrm{~mm}$} & N1 & 11 & 6.0 & 7.34 & 4.75 & 17.59 & 0.0165 & 6.94 & 0.67 \\
\hline & $\mathrm{N} 2$ & 11 & 6.4 & 7.84 & 4.69 & 17.06 & 0.0162 & 7.76 & 0.71 \\
\hline & N3 & 11 & 6.1 & 7.72 & 4.76 & 18.08 & 0.0165 & 7.00 & 0.70 \\
\hline & Average & & 6.2 & 7.63 & 4.74 & 17.58 & 0.0164 & 7.22 & 0.69 \\
\hline
\end{tabular}

after the first slippage of the steel, friction, and the most efficient contribution of mechanical bonding in the form of bar ribs. Textile reinforcement, on the other hand, is composed of thousands of filaments, only the most external of which are in contact with the matrix. In addition, only a part of the filaments is anchored in the cement paste and thus the inner filaments can slip easily within the roving. The bond may also be influenced by fabric coating. In Banholzer's [16] Yarn-Matrix-Bond theory, developed from an experimental investigation into filament pull-out, the roving is schematized as a cylindrical structure comprised of concentric rings, each one composed of several filaments (Fig. 9). The roving failure mechanism is initiated by the failure of the outer filament ring, followed by that of each adjacent layer until reaching the core filaments at the ultimate collapse. According to several research investigations, the easiest way to highlight bond failure is via computation of the peak load of the AR-glass fabric, with and without the matrix. This method reflects the extremely fine matrix used which prevents any significant contribution from aggregate interlocking after cracking, as well as the lack of any random fibre contribution due to the presence of the fabric as the only reinforcement. In the present study, an effectiveness factor $(\mathrm{EF})$ was determined by dividing F1-2 fabrics peak load by twice the peak load experimentally calculated by stretching only fabric F1. If EF is less than 1 (as in this case), a bond weakness is immediately highlighted, whereas values of EF larger than unity indicate the occurrence of a positive interaction with the matrix which exerts a tension stiffening effect. The computed EF factors for each fabric type and configuration are shown in Tables 7, 8, 9, 10, 11, and 12 .

Looking at these tables, it can be seen that the 2 layers configuration generally resulted in a higher TRC strength than the 2 fabrics configuration. This likely reflects the fact that despite having the same reinforcement ratio, the former has a larger contact surface area between matrix and reinforcement. The change from 2 fabrics to 2 layers led to an increase in TRC tensile strength from 13.52 to $17.88 \mathrm{MPa}$ for fabric F1, and from 22.37 to $24.42 \mathrm{MPa}$ for fabric F2. Crack distance decreased with increasing reinforcement ratio until cracking appeared at each weft roving, maximizing the mechanical performance of the composite (Figs. 6b, 7b). The ultimate strains reached in the 2 fabrics and 2 layers configurations were comparable, with both greater than $2 \%$. When typical TRC behaviour was achieved, all tests exhibited good repeatability, with scattering always less than $1 \%$.

Fabric F3, characterized by a cross-sectional area equal to $94 \%$ of that represented by two F2 fabrics, was also analyzed. A comparison between the results achieved using two layers of fabric F2 and those using one central layer of fabric F3 is presented in Fig. 8a. As can be seen from this figure, a multicracking phase 
Table 10 Test results for specimens reinforced with fabric F3-1 fabric (curing conditions varied)

\begin{tabular}{llllllllll}
\hline & Specimen & Batch & $t(\mathrm{~mm})$ & $P_{\max }(\mathrm{kN})$ & $\delta_{\mathrm{u}}(\mathrm{mm})$ & $\sigma_{\max }(\mathrm{MPa})$ & $\delta_{\mathrm{u}} / 1(-)$ & $\sigma_{\mathrm{I}}(\mathrm{MPa})$ & $\mathrm{EF}(-)$ \\
\hline Water & $\mathrm{N} 1$ & 10 & 6.2 & 7.86 & 7.80 & 17.97 & 0.0270 & 3.48 & 0.71 \\
& $\mathrm{~N} 2$ & 10 & 6.3 & 7.32 & 7.66 & 16.45 & 0.0265 & 4.36 & 0.66 \\
& $\mathrm{~N} 3$ & 10 & 6.1 & 7.35 & 6.85 & 16.97 & 0.0237 & 4.26 & 0.67 \\
& Average & & 6.2 & 7.51 & 7.44 & 17.13 & 0.0257 & 4.03 & 0.68 \\
$60{ }^{\circ} \mathrm{C}$ & N1 & 12 & 6.5 & 10.43 & 7.75 & 22.86 & 0.0269 & 5.14 & 0.95 \\
& N2 & 12 & 6.5 & 10.30 & 6.70 & 22.50 & 0.0233 & 5.54 & 0.93 \\
& N3 & 12 & 6.5 & 10.01 & 7.29 & 21.84 & 0.0253 & 5.53 & 0.91 \\
& Average & & 6.5 & 10.25 & 7.25 & 22.40 & 0.0252 & 5.40 & 0.93 \\
Air & N1 & 13 & 6.0 & 11.01 & 6.47 & 26.04 & 0.0225 & 7.31 & 1.00 \\
& N2 & 13 & 6.1 & 12.13 & 7.91 & 28.21 & 0.0275 & 5.85 & 1.10 \\
& N3 & 13 & 6.4 & $7.81^{\mathrm{a}}$ & $4.48^{\mathrm{a}}$ & $17.25^{\mathrm{a}}$ & $0.0157^{\mathrm{a}}$ & 5.14 & $0.71^{\mathrm{a}}$ \\
& Average & & 6.2 & 11.57 & 7.19 & 27.13 & 0.0250 & 6.10 & 1.05 \\
\hline
\end{tabular}

${ }^{a}$ Problem occurred during the test (crack formation in the clamping area)—values not included in calculation of the average

Table 11 Test results for specimens reinforced with fabric F3-1 fabric (displacement rate varied)

\begin{tabular}{llllllllll}
\hline & Specimen & Batch & $t(\mathrm{~mm})$ & $P_{\max }(\mathrm{kN})$ & $\delta_{\mathrm{u}}(\mathrm{mm})$ & $\sigma_{\max }(\mathrm{MPa})$ & $\delta_{\mathrm{u}} / 1(-)$ & $\sigma_{\mathrm{I}}(\mathrm{MPa})$ & $\mathrm{EF}(-)$ \\
\hline $2 \mathrm{~mm} / \mathrm{s}$ & $\mathrm{N} 1$ & 10 & 6.4 & 10.20 & 8.61 & 22.62 & 0.0298 & 5.06 & 0.93 \\
& $\mathrm{~N} 2$ & 10 & 6.2 & 9.62 & 7.84 & 22.05 & 0.0273 & 6.07 & 0.87 \\
& $\mathrm{~N} 3$ & 10 & 6.4 & 10.10 & 8.02 & 22.57 & 0.0277 & 5.59 & 0.92 \\
& Average & & 6.3 & 9.97 & 8.15 & 22.42 & 0.0283 & 5.57 & 0.91 \\
$2 \times 10^{-2} \mathrm{~mm} / \mathrm{s}$ & $\mathrm{N} 1$ & 10 & 6.2 & 7.86 & 7.80 & 17.97 & 0.0270 & 3.48 & 0.71 \\
& N2 & 10 & 6.3 & 7.32 & 7.66 & 16.45 & 0.0265 & 4.36 & 0.66 \\
& N3 & 10 & 6.1 & 7.35 & 6.85 & 16.97 & 0.0237 & 4.26 & 0.67 \\
& Average & & 6.2 & 7.51 & 7.44 & 17.13 & 0.0257 & 4.03 & 0.68 \\
$2 \times 10^{-4} \mathrm{~mm} / \mathrm{s}$ & N1 & 10 & 6.4 & 5.24 & 6.58 & 11.66 & 0.0227 & 3.73 & 0.48 \\
& N2 & 10 & 6.5 & 6.85 & 7.15 & 14.98 & 0.0247 & 4.74 & 0.62 \\
& N3 & 10 & 6.9 & 6.12 & 5.08 & 12.64 & 0.0175 & 5.12 & 0.56 \\
& Average & & 6.6 & 6.07 & 6.27 & 13.10 & 0.0217 & 4.53 & 0.55 \\
\hline
\end{tabular}

commenced after the first linear branch in both cases. However, the first cracking strength for fabric F2 was higher than that for fabric F3 (Table 9-10 mm); this difference is comparable to inter-batch variation in concrete tensile strength and is accompanied by a further decrease in EF to 0.68.

This EF decrease also affected the stiffness of the last branch, in which no further cracking occurred. The peak strength reached was equal to $25 \mathrm{MPa}$ for F2 and $15 \mathrm{MPa}$ for F3, while the ultimate strain was larger than $2 \%$. The cracking pattern observed in F3 samples was characterized by a larger distance between cracks (about every $30 \mathrm{~mm}$ ). Significantly, the bond area in contact with the cementitious matrix was larger in the case of 2 layers, resulting in the roving being better anchored to the matrix.

\subsection{Influence of fabric geometry}

Bonding in a cementitious matrix is quite a complex issue, being influenced by both fabric geometry and the matrix itself. As discussed earlier, textile fabrics typically have no homogeneous cross-section and their bond behaviour is thus governed by the properties of the inner and outer filaments, while the influence of weft as a direct anchor also plays an important role in fabric global bond-slip behaviour. In order to analyze fabric bonding, the contribution offered by yarns perpendicular to load 
Table 12 Test results for specimens reinforced with fabric F3-1 fabric (specimen size varied)

\begin{tabular}{llllllllll}
\hline & Specimen & Batch & $t(\mathrm{~mm})$ & $P_{\max }(\mathrm{kN})$ & $\delta_{\mathrm{u}}(\mathrm{mm})$ & $\sigma_{\max }(\mathrm{MPa})$ & $\delta_{\mathrm{u}} / 1(-)$ & $\sigma_{\mathrm{I}}(\mathrm{MPa})$ & $\mathrm{EF}(-)$ \\
\hline $290 \mathrm{~mm}$ & $\mathrm{~N} 1$ & 10 & 6.2 & 7.86 & 7.80 & 17.97 & 0.0270 & 3.48 & 0.71 \\
& $\mathrm{~N} 2$ & 10 & 6.3 & 7.32 & 7.66 & 16.45 & 0.0265 & 4.36 & 0.66 \\
& $\mathrm{~N} 3$ & 10 & 6.1 & 7.35 & 6.85 & 16.97 & 0.0237 & 4.26 & 0.67 \\
& Average & & 6.2 & 7.51 & 7.44 & 17.13 & 0.0257 & 4.03 & 0.68 \\
$150 \mathrm{~mm}$ & $\mathrm{~N} 1$ & 14 & 6.8 & 10.41 & 4.49 & 21.92 & 0.0304 & 6.41 & $0.94^{\mathrm{a}}$ \\
& $\mathrm{N} 2$ & 14 & 6.5 & 9.56 & 3.75 & 20.65 & 0.0259 & 6.24 & $0.87^{\mathrm{a}}$ \\
& $\mathrm{N} 3$ & 14 & 6.3 & 8.56 & 3.18 & 19.43 & 0.0219 & 4.50 & $0.78^{\mathrm{a}}$ \\
& Average & & 6.5 & 9.51 & 3.81 & 20.67 & 0.0261 & 5.72 & 0.86 \\
& N1 & 14 & 6.5 & 10.63 & 3.26 & 23.38 & 0.0450 & 5.70 & $0.96^{\mathrm{a}}$ \\
& N2 & 14 & 6.2 & 7.93 & 2.17 & 17.75 & 0.0294 & 5.09 & $0.72^{\mathrm{a}}$ \\
& N3 & 14 & 6.4 & 9.32 & 2.68 & 20.82 & 0.0355 & 4.79 & $0.85^{\mathrm{a}}$ \\
& Average & & 6.4 & 9.29 & 2.70 & 20.65 & 0.0366 & 5.19 & 0.84 \\
\hline
\end{tabular}

a The strength of the $400 \times 70 \mathrm{~mm}$ fabric was considered

Fig. 10 Influence of fabric geometry (different weft spacing) for a specimen reinforced with F3-1 fabric: nominal stress versus normalized displacement curves in uniaxial tension (a) and specimen cracking pattern (b)

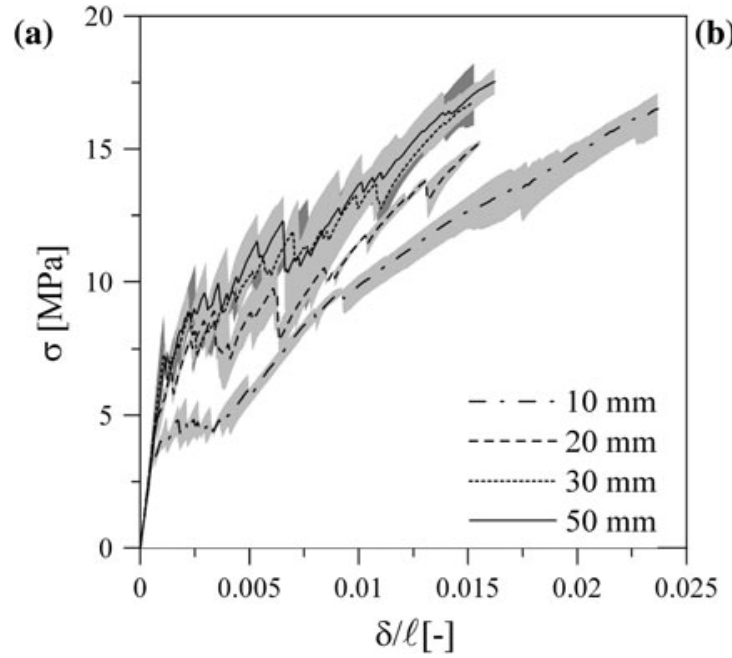

(b)
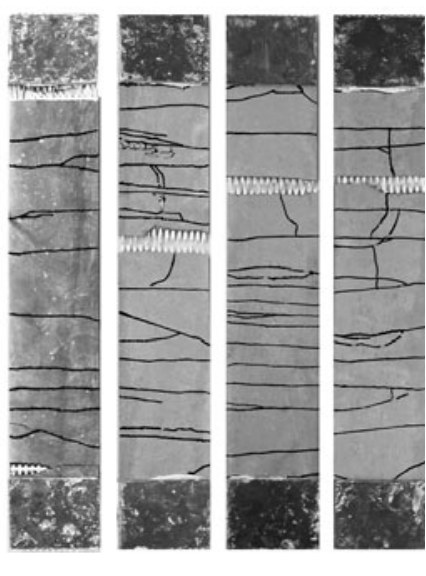

$10 \mathrm{~mm} \quad 20 \mathrm{~mm} \quad 30 \mathrm{~mm} \quad 50 \mathrm{~mm}$ direction and by roving joint connection must be considered. Soranakom and Mobasher [4] developed a schematic model illustrating the sequential stages of debonding and joint failure. As the load increases, a series of debonding steps is expected, starting with longitudinal debonding along the roving parallel to load direction until reaching the anchoring point, represented by the node at which warp and weft are connected.

Fabrics with the same warp cross-section but different weft spacing were investigated in the present study, with four weft spacings in fabric F3 considered: 10, 20, 30 and $50 \mathrm{~mm}$. Three nominally identical tests were performed on as many specimens reinforced with each of these fabric-spacing types. The obtained results in terms of nominal stress versus normalized displacement are reported in Fig. 10a and Table 9. The lowest first cracking strength was observed in specimens containing fabric with the smallest weft spacing (about $3 \mathrm{MPa}$ ), because of the reduced effective tension stiffening induced along the warp. In terms of bond effectiveness the weft can play a double role: on one hand it can act as a direct anchorage to warp sliding, while on the other it may represent a defect in the matrix cross-section that could favour both warp delamination and/or crack propagation in the weft direction. In fabrics with small weft spacing, the weft defect action prevailed over the contribution of weft as direct anchor. In contrast, when weft spacing was wider the tension stiffening action prevailed, with first cracking strength reaching values 
Fig. 11 Influence of curing conditions on F3-1 fabric specimens: nominal stress versus normalized displacement curves in uniaxial tension (a) and specimen cracking pattern (b)

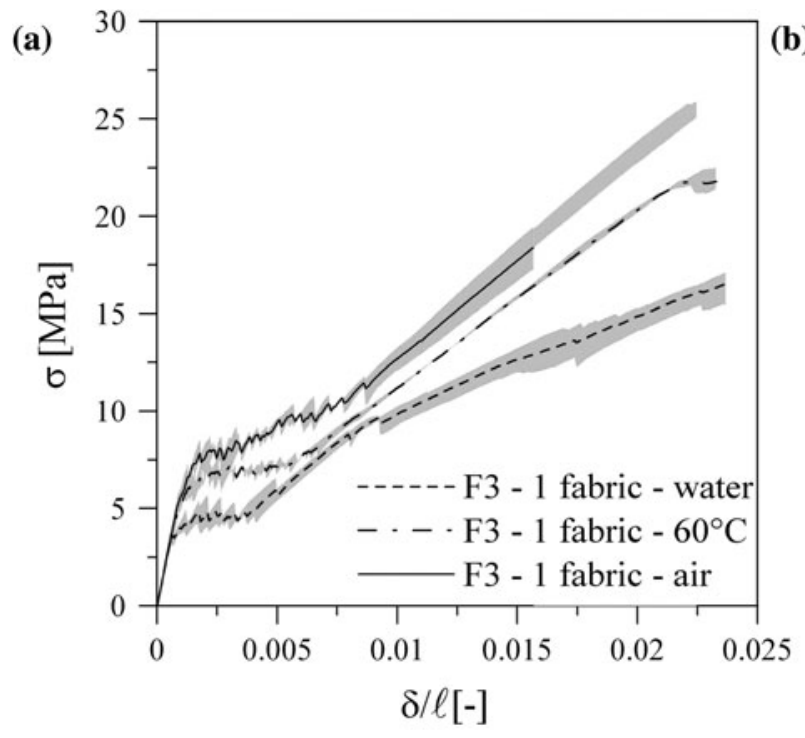

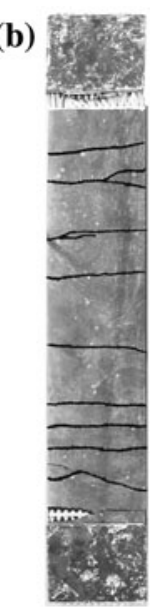
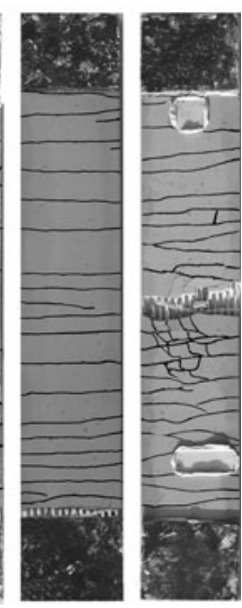

F3
fabric

F3

1 fabric $60^{\circ} \mathrm{C}$
F3
fabric
air of around $7 \mathrm{MPa}$. In the case of 30 and $50 \mathrm{~mm}$ weft spacing, the stiffness of the multicracking branch was higher because the process of longitudinal delamination was prevented by the presence of a longer bond length. In terms of ductility, specimens with $10 \mathrm{~mm}$ weft spacing were characterized by larger ultimate strain because longitudinal crack propagation, caused by the dense presence of weft-derived defects, allowed the roving to stretch. Analysis of Fig. 10b, which shows the different cracking patterns, reveals that cracks also appeared between the weft rovings in the $30 \mathrm{~mm}$ weft spacing specimens. Significantly, the peak load was roughly the same for all weft spacing configurations; weft spacing variation thus affects only tension stiffening and not the value of the EF.

\subsection{Effect of curing method on TRC performance}

A variety of curing methods were investigated in order to analyze the influence of different shrinkage conditions on the bonding mechanism. Specimens $400 \times 70 \times 6 \mathrm{~mm}^{3}$ in size and reinforced with F3-1 fabric (reinforcement ratio equal to $3.07 \%$ ) were cured using one of three methods: water or air for 28 days, and 6 days at $60{ }^{\circ} \mathrm{C}$. The latter scenario corresponds to a curing time of 28 days when the Model Code strengthtime curve valid for concrete is assumed. The obtained results in terms of stress versus nominal displacement curves are shown in Fig. 11, with the numerical values summarized in Table 10. Specimens cured in water exhibited the lowest first cracking strength and a final branch with the lowest stiffness. One possible reason for this is that the water penetration between roving and matrix makes telescopic failure easier, damages the fabric and reduces the bond strength. The samples cured in free air exhibited the best performance in terms of first cracking strength, ultimate tensile strength and cracking pattern (Fig. 11b); this phenomenon can be explained by the more significant shrinkage produced using this method, which improves the bond between matrix and fabric. As a matter of fact, looking at the matrix interface sleeve in which the glass roving is embedded, when the concrete is subjected to a contraction due to shrinkage, a normal stress takes place and consequently friction increases. The first cracking strength obtained in this case is comparable with the value of tensile strength $f_{\mathrm{ctm}}$ (Eq. 1) observed during bending tests (around $6 \mathrm{MPa}-$ Tables 3,10). The average curve for specimens cured at $60{ }^{\circ} \mathrm{C}$ for 6 days falls between those of the two other methods. This intermediate behaviour reflects the shrinkage compensation obtained via oven curing and the slow initial hydration of slag [17].

\subsection{Displacement rate}

The mechanical behaviour of cement-based materials is known to be widely dependent on strain rate. Although several experiments have been performed on concretes 
Fig. 12 Influence of test displacement rate $(\dot{\delta})$ for F31 fabric specimens. Nominal stress versus normalized displacement curves in uniaxial tension (a) and specimen cracking pattern (b) (a)

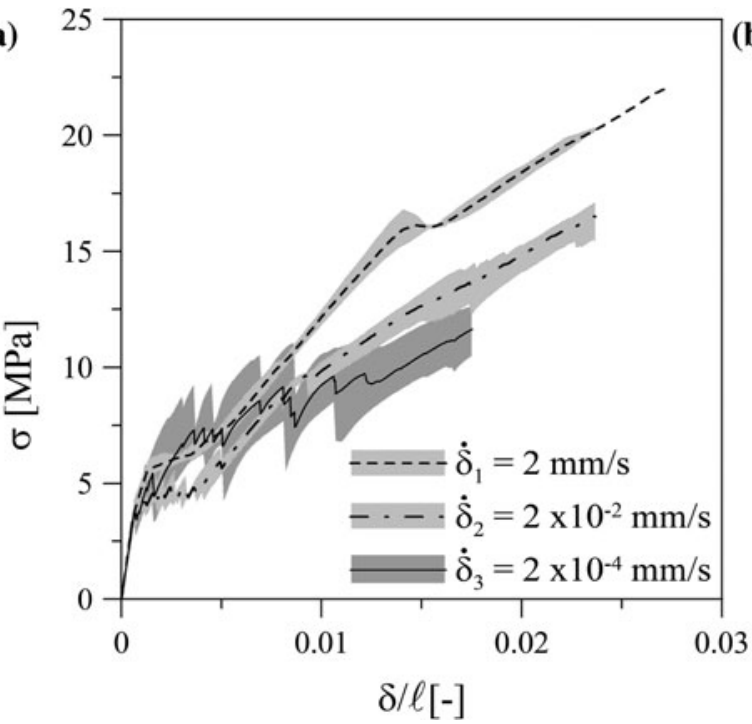

(b)

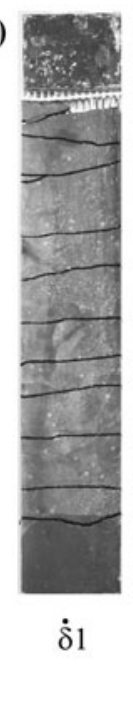

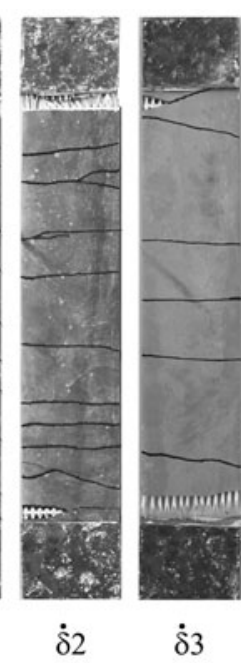

and fibre-reinforced cementitious composites (looking at impact problems at different strain rates), relatively few have considered the creep effect in TRC (e.g. de Andrade Silva et al. [18]). The displacement rate commonly adopted by TRC researchers-and also used in all the other tests presented in this paper-is equal to $2 \times 10^{-2} \mathrm{~mm} / \mathrm{s}$. In order to understand the influence of strain rate on TRC behaviour in static and quasi-static regimes, different displacement rates, corresponding to different strain rates, were considered. In particular, in addition to the usual stroke rate, two other displacement rates were analyzed (two orders of magnitude higher and lower, respectively):

- $2 \mathrm{~mm} / \mathrm{s}\left(0.69 \times 10^{-2} \mathrm{~s}^{-1}\right)$;

$-\quad 2 \times 10^{-2} \mathrm{~mm} / \mathrm{s}\left(0.69 \times 10^{-4} \mathrm{~s}^{-1}\right)$;

$-2 \times 10^{-4} \mathrm{~mm} / \mathrm{s}\left(0.69 \times 10^{-6} \mathrm{~s}^{-1}\right)$.

The strain rates (in brackets) were obtained by dividing the displacement rate by the average gauge length of the specimens (e.g. $290 \mathrm{~mm}$ ).

For each displacement rate, three specimens reinforced with F3-1 fabric were tested, with the obtained results shown in Table 11, including a summary of the maximum load, corresponding ultimate displacement, maximum stress, corresponding strain and the first cracking strength for each specimen. Figure 12 displays average stress versus strain curves and representative specimen crack patterns for each displacement rate.

At the higher displacement rate $(2 \mathrm{~mm} / \mathrm{s})$, typical TRC behaviour was observed, i.e. characterized by three branches. The first of these corresponded to linear-elastic behaviour, and was followed by the formation of multiple cracking after the occurrence of first cracking at around $6.4 \mathrm{MPa}$; during the final stage, after a low stress increase, the cracks widened until specimen failure. In all specimens, but especially in numbers 2 and 3, a change in stiffness at about $16 \mathrm{MPa}$ of nominal stress was observed. This discontinuity could be related to an apparent stiffness increase due to the creep effect. Significantly, the final slopes of all the strain rates investigated were almost identical.

Typical TRC behaviour was also observed at the intermediate displacement rate $\left(2 \times 10^{-2} \mathrm{~mm} / \mathrm{s}\right)$, the speed most commonly employed in TRC tensile tests. In this case the second phase commenced at a lower stress value (about $4 \mathrm{MPa}$ ), while the peak stress reached was lower in comparison to that seen at the higher displacement rate (about 17 and 22.4 MPa, respectively).

For the lowest displacement rate considered $\left(2 \times 10^{-4} \mathrm{~mm} / \mathrm{s}\right)$ the three branches could not be clearly identified, with only a multicracking phase up to failure observed after an initial linear-elastic phase. At this displacement rate, a reduction in bond strength between matrix and fabric was observed after the occurrence of first cracking (at 3.7-5.1 MPa), followed by sliding. The strength reached in this last test was close to $13 \mathrm{MPa}$.

Looking at the average values in Table 11 and the TRC behaviour shown in Fig. 12, a loss in strength and ductility with decreasing displacement rate is apparent. 
Fig. 13 Influence of specimen size for F3-1 fabric reinforcement: load versus displacement curves in uniaxial tension (a), nominal stress versus normalized displacement curves in uniaxial tension (b), specimen cracking pattern (c) and fitting with Bažant's size effect law (d)
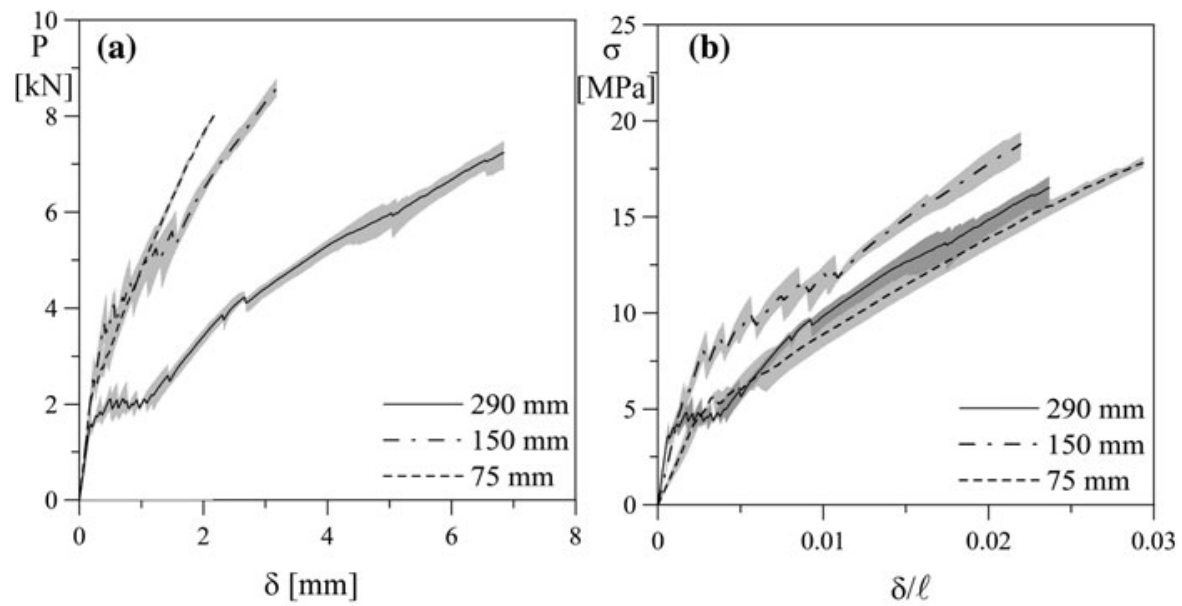

(c)
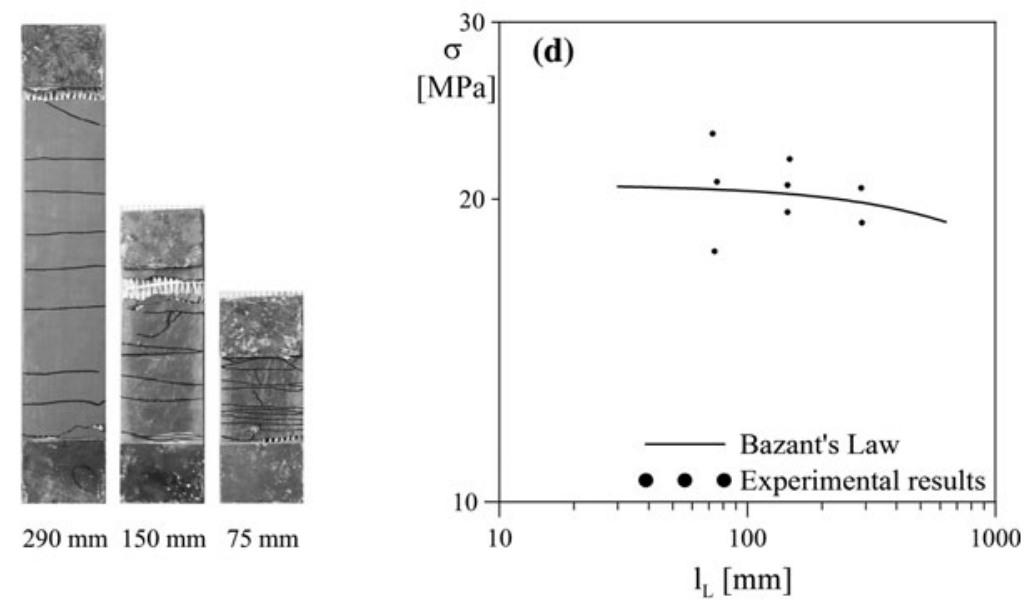

In addition, a coarser specimen cracking pattern was exhibited with the decrease from $10^{-2}$ to $10^{-6} \mathrm{~s}^{-1}$ (Fig. 12b), while a strength reduction of around $23.5 \%$ was observed after the displacement rate was decreased from $10^{-2}$ to $10^{-4} \mathrm{~s}^{-1}$ and from $10^{-4}$ to $10^{-6} \mathrm{~s}^{-1}$.

The significant role played by strain rate in the present study could be related to both the glass material employed and the interface bond strength. Further research is thus required to better understand the roles of each mechanism.

\subsection{Size effect}

In order to appreciate the role of the size effect in uniaxial tension hardening derived from the multicracking phenomenon controlled by bond effectiveness, three different specimen lengths were investigated: 290, 150 and $75 \mathrm{~mm}$. All specimens were reinforced with F3-1 fabric (reinforcement ratio equal to $3.07 \%$ ), with the results presented in Fig. 13 and Table 12. Figure 13a shows that all the average curves obtained for the different lengths overlap for displacement values lower than $0.2 \mathrm{~mm}$. This likely reflects the fact that the displacement measured by the mechanical press is expressed as the sum of two components: specimen elongation and specimen sliding in the clamps. In fact, in the first linear-elastic branch the contribution of sliding predominates, so the curves appear to overlap. However, closer analysis of the stress versus strain curves obtained by dividing relative displacement by free length reveals variation in specimen initial stiffness (Fig. 13b). As a result, although the initial slope of the nominal stress versus normalized displacement curves should represent the elastic modulus of the concrete, which was the same for all specimens, the results are altered due to specimen sliding between the clamps. 


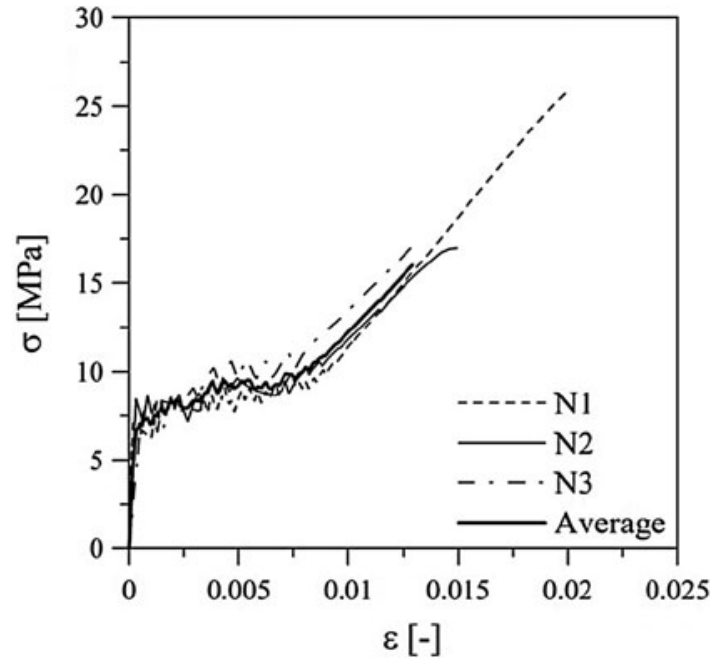

Fig. 14 F3-1 fabric specimens cured in air: nominal stress versus strain curves in uniaxial tension

Table 13 Test results for specimens reinforced with F3-1 fabric and cured in air: eccentricity, ultimate strain and first cracking strain

\begin{tabular}{llll}
\hline Specimen & $e(\mathrm{~mm})$ & $\varepsilon_{\mathrm{u}}(-)$ & $\varepsilon_{\mathrm{I}}(-)$ \\
\hline $\mathrm{N} 1$ & 0.8 & 0.0202 & 0.0002 \\
$\mathrm{~N} 2$ & 0.4 & $--^{\mathrm{a}}$ & 0.0002 \\
$\mathrm{~N} 3$ & 1.6 & $-{ }^{\mathrm{a}}$ & 0.0004 \\
Average & 0.9 & - & 0.0003 \\
\hline
\end{tabular}

${ }^{a}$ Detachment of the gauge

With reference to post-cracking behaviour, the curves reveal tension stiffening to be controlled by specimen length: the longer the specimen, the smaller the ductility (Table 12). A finer cracking pattern (Fig. 13c) was observed in shorter specimens, correlating with the previous results. In addition, peak load was barely affected by specimen length, as indicated by the results of fitting with Bažant's size effect law (Fig. 13d) [19].

\subsection{Normalized displacement and strain}

To better understand the influence of sliding on pressmeasured displacement, the three nominally identical specimens reinforced with F3-1 fabric and cured in air (Table 10-air) were instrumented with two LVDT transducers, one on the front and one on the rear side, during the tensile test. The length of the gauge astride the middle of each specimen was around $218 \mathrm{~mm}$. As Fig. 14 shows, the nominal stress versus strain curves overlap to a fairly high degree, with the strain obtained by dividing the average displacement measured by the LVDTs (average of front and rear side values) by gauge length. In this case the slope of the initial linearelastic branch represents the Young's modulus of the concrete, a value of around $46 \mathrm{GPa}$. The measured first cracking strain and, where possible, ultimate strain, are summarized in Table 13.

Figure 15a presents a comparison between the nominal stress versus normalized displacement (stroke displacement divided by free length) and the nominal stress versus strain curves of specimen N1. Considering the specimen and its sliding as two springs in series, it is then possible to calculate the stiffness reduction due to sliding at variable loads. Figure 15a also shows that the multicracking phase (branch IIa) was partially increased in terms of strain range, while the cracked branch (IIb) was stiffer when represented by the stress-strain curve.
Fig. 15 F3-1 fabric specimens cured in air, specimen N1: comparison between nominal stress versus normalized displacement and nominal stress versus strain curves in uniaxial tension (a); initial linear elastic branch of nominal stress versus strain curve in uniaxial tension: front and back LVDT (b)

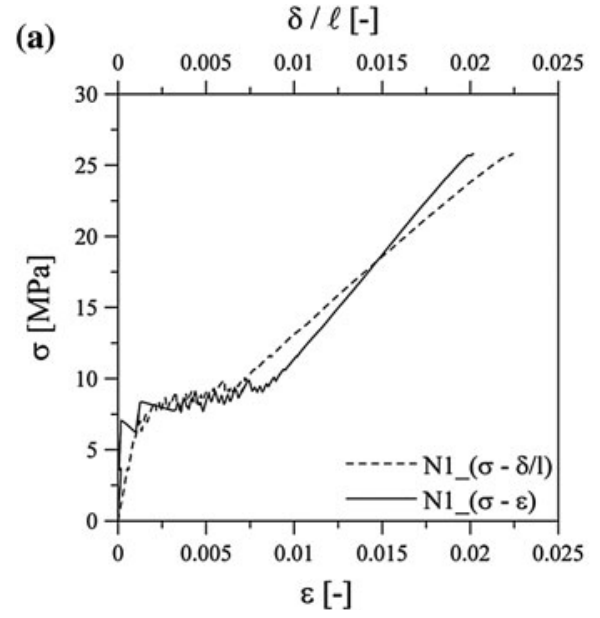

(b)

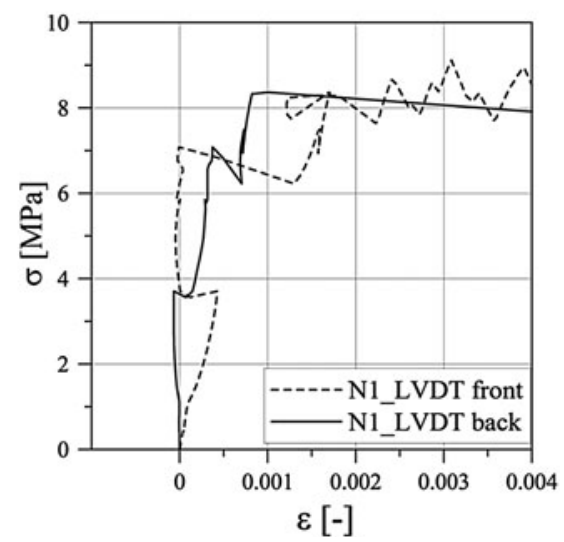


Figure $15 \mathrm{~b}$ presents an enlarged view of the initial linear-elastic branch of the stress versus strain curve. Analysis of this figure reveals that the specimen in question was not perfectly loaded in uniaxial tension, with a bending moment due to the initial loss in planarity (related to shrinkage) introducing an eccentricity in the order of $1 \mathrm{~mm}$ (Table 13). In this case the LVDT located on the rear side of the specimen recorded compressive strains and the front one tensile strains. This flexure vanished upon crack development.

\section{Conclusions}

From the experimental results presented here, which focus on uniaxial tension behaviour in the direction of warp, a number of important remarks can be made in terms of answering the questions posed in the introduction:

1. The behaviour of TRC is strongly influenced by the level of reinforcement introduced, with both the equivalent cross-section and the bond surface of the warp roving playing an important role. In contrast, the weft roving seems to mainly control cracking distance and therefore overall ductility. As a result, with reference to a single fabric, a limit reinforcement ratio can be detected via the computation of an $\mathrm{EF}$, based on the ratio between the peak loads of the TRC composite and AR-glass fabric. When the value of EF is less than 1, a progressive reduction in effectiveness is experienced. The smallest value of EF measured in the present experimental investigation was 0.67 for a reinforcement ratio of about $3.20 \%$. The EF value can be increased by increasing the number of fabric layers; in this case layers should be separated as full overlap can significantly reduce $\mathrm{EF}$ due to the loss of bond surface. Analysis of the employed leno weave assembling technique resulted in the identification of a minimum weft spacing able to prevent fabric sliding, with the value detected for the TRC used in the present study close to $30 \mathrm{~mm}$. Smaller values may favour delamination effects.

2. Since curing conditions can affect matrix shrinkage, they are also associated with the bond phenomenon in the composite material. The greater the shrinkage, the greater the bond strength that develops; consequently both the first cracking and peak strength increase. Three curing methods were investigated: 28 days at room temperature, 6 days at $60{ }^{\circ} \mathrm{C}$ and 28 days immersed in water. The best solution in terms of peak strength was achieved via the first method.

3. As with other cement-based materials, TRC behaviour depends on strain rate. In the present study, a loss in strength and ductility with decreasing displacement rate was also associated with a coarser cracking pattern. An apparent stiffness increase due to creep effects was identified, although further research regarding this phenomenon is required.

4. No significant peak strength reduction was observed in terms of the size effect, despite the experimental results fitting reasonably well with Bažant's law. Here specimen size partially affected the post cracking branch, with a reduction in ductility observed with increasing specimen size. Finally, for specimen lengths larger than twice specimen width, negligible variation in the first cracking strength was found.

Identification of the uniaxial tension constitutive law should be carried out via measurement of the relative displacement between two points on opposite sides of the specimen, excluding the end zones. Strain evolution identified using stroke measurement not only prevents the computation of a reliable elastic precrack stiffness value, but also introduces not negligible variation in the multicracking and cracked phases.

Acknowledgments The authors would like to thank the Gavazzi company for its cooperation and for supplying the AR glass fabrics. This research was financially supported by the Lombardy Region as part of the "Advanced cement based materials: concept and structural applications" project (MAN21-CUP: E75E10000290009).

\section{References}

1. Mobasher B, Peled A, Pahilajani J (2006) Distributed cracking and stiffness degradation in fabric-cement composites. Mater Struct 39:317-331. doi:10.1617/s11527005-9005-8

2. Peled A, Sueki S, Mobasher B (2006) Bonding in fabriccement systems: effects of fabrication methods. Cem Concr Res 36:1661-1671. doi:10.1016/j.cemconres.2006.05.009

3. Peled A, Zaguri E, Marom G (2008) Bonding characteristics of multifilament polymer yarns and cement matrices. 
Composites A 39:930-939. doi:10.1016/j.compositesa. 2008.03.012

4. Soranakom C, Mobasher B (2009) Geometrical and mechanical aspects of fabric bonding and pullout in cement composites. Mater Struct 42:765-777. doi:10.1617/s11527008-9422-6

5. Sueki S, Soranakom C, Mobasher B, Peled A (2007) Pullout-slip response of fabrics embedded in a cement paste matrix. J Mater Civ Eng 19:718-727. doi:10.1061/(ASCE) 0899-1561(2007)19:9(718

6. Zastrau B, Richter M, Lepenies I (2003) On the analytical solution of pullout phenomena in textile reinforced concrete. J Eng Mater Technol 125:38-43. doi:10.1115/ 1.1526125

7. Orlowsky J, Raupach M (2008) Durability model for AR-glass fibres in textile reinforced concrete. Mater Struc 41:1225-1233. doi:10.1617/s11527-007-9321-2

8. Purnell P, Beddows J (2005) Durability and simulated ageing of new matrix glass fibre reinforced concrete. Cem Concr Compos 27:875-884. doi:10.1016/j.cemconcomp. 2005.04.002

9. Butler M, Mechtcherine V, Hempel S (2010) Durability of textile reinforced concrete made with AR glass fibre: effect of the matrix composition. Mater Struc 43:1351-1368. doi: 10.1617/s11527-010-9586-8

10. UNI EN 196 (2005) Method of testing cement-part 1: Determination of strength

11. fib (2012) Model code 2010_final draft, vol 1. Model Code
12. Curbach M, Jesse F (1999) Lecture No. 513: basic tensile tests on strain specimens of textile-reinforced concrete. In: Techtextil Symposium 1999, Frankfurt

13. Harting J, Jesse F, Schicktanz K, Haussler-Combe U (2011) Influence of experimental setups on the apparent uniaxial tensile load-bearing capacity of textile reinforced concrete specimens. Mater Struct 45:433-446. doi:10.1617/s11527011-9775-0

14. Hegger J, Will N, Curbach M, Jesse F (2004) Tragverhalten von textilbewehrtem Beton. Beton-und Stahlbetonbau 99:452-455. doi:10.1002/best.200490115

15. Ohno S, Hannant DJ (1994) Modelling the stress-strain response of continuous fiber reinforced cement composites. ACI Mater J 91:306-312

16. Banholzer B (2004) Bond Behaviour of Multifilament Yarn Embedded in Cementitious Matrix. In: Schriftenreihe Aachener Beiträge zur Bauforschung, Institut für Bauforschung der RWTH Aachen, Nr. 12, zuglr. Dissertation

17. Neville AM (1996) Properties of concrete. Wiley, New York

18. de Andrade Silva F, Butler M, Mechtcherine V, Zhu D, Mobasher B (2010) Strain rate effect on the tensile behavior of textile-reinforced concrete under static and dynamic loading. Mater Sci Eng A 528:1727-1734. doi:10.1016/ jmsea.2010.11.014

19. Bažant ZP (1984) Size effect in blunt fracture: concrete, rock, metal. J Eng Mech 110(4):518-535. doi:10.1061/ (ASCE)0733-9399(1984)110:4(518 